\title{
Tecnologia, experiência e memória ${ }^{1}$
}

Aécio Amaral Jr*

\begin{abstract}
Resumo $\mathrm{O}$ artigo investiga a estruturação de uma nova cultura de memória, a qual inverte a lógica metafísica com que se pensou a relação entre tecnologia e experiência nas ciências sociais. Com as recentes tecnologias da vida e da informação, a concepção do corpo humano como algo que se constitui à margem de um aparato tecnológico declina em credibilidade. Com isso, um dos principais projetos da metafísica ocidental, a saber, a estruturação de um campo de experiência e conhecimento livre de suportes técnicos, malogra em seu humanismo tecnofóbico. A partir de uma apreciação do conto "Memento mori", de Jonathan Nolan, e do filme Amnésia, de Christopher Nolan, analiso a relação entre memória e escritura, corpo e arquivo na contemporaneidade. O objetivo é perceber as tensões e oscilações implícitas na tentativa de instauração de uma mnemotécnica pretensamente pós-humana ou pós-orgânica.
\end{abstract}

\section{Palavras-chave tecnologia, experiência, memória, humanismo, pós-humanismo}

\begin{abstract}
The article investigates the structuration of a new culture of memory which inverts the metaphysical logic which has informed the understanding of the relation between technology and experience in the social sciences. With recent developments in information and life technologies, the conception of the human body as something which is constituted on the margin of the technological apparatus has declined in credibility. This way, one of the principal projects of western metaphysics, the structuration of a field of experience and knowledge free of technical supports, is thwarted in its technophobic humanism. Starting from an appreciation of the short story "Memento mori", of Jonathan Nolan, and the film Memento, by Christopher Nolan, I analyze the contemporary relation between memory and writing, body and archive. The objective is to perceive the tensions and oscillations implicit in the attempt to establish an intentionally post human and post-organic mnemotechnic.
\end{abstract}

Keywords technology, experience, memory, humanism, post humanism

$\mathrm{Na}$ agenda das ciências sociais contemporâneas, estamos longe de estabelecer algum consenso no que diz respeito à forma como as recentes tecnologias digitais redimensionam a estruturação do social e remodelam os aspectos existencial e político da vida em sociedade. Não há dúvida quanto ao fato de que as tecnologias digitais lastreiam uma série de eventos políticos e culturais que de algum modo nos colocam numa situação de aporia diante dos conteúdos ordenadores do projeto civilizatório da modernidade e de padrões de sociabilidade que se assentavam na lógica da presença. Mas encontramos vários desacordos quando indagamos a respeito do novo padrão de experiência que está por trás dos desdobramentos da tecnociência e da tecnocultura.

\footnotetext{
${ }^{1}$ Texto apresentado no GT Sociedade de Informação do XII Congresso Brasileiro de Sociologia, ocorrido em Belo Horizonte-MG, entre os dias 31 de maio e 3 de junho de 2005.

* Aécio Amaral Jr é professor assistente do Departamento de Ciências Sociais, CCHLA/UFPB.
} 
Neste texto, gostaria de propor uma especulação a respeito da relação entre experiência, técnica e memória. Tal relação deve ser pensada a partir do caráter constitutivo da técnica em relação ao humano, embora o faça buscando apontar incoerências presentes tanto no humanismo antropocêntrico quanto no discurso ideológico pós-humanista que busca suplantá-lo. Sugiro que a noção de experiência, aliada à lógica derridiana da suplementaridade técnica, pode nos auxiliar na empreitada.

\title{
Corporificação e experiência
}

A noção de experiência sofre um deslocamento significativo nas ciências sociais a partir da chamada virada lingüística, seja em sua versão habermasiana, foucaultiana ou pós-estruturalista. Ao destinar a determinação da consciência ao plano da linguagem, traço comum às três perspectivas, não raro os teóricos da virada lingüística são acusados de negligenciar a noção de experiência. Gostaria de propor como hipótese norteadora desse artigo a idéia de que a noção de experiência pode ser recuperada para o entendimento de uma série de fenômenos característicos da chamada sociedade de informação, desde que obviamente desvinculada da filosofia da consciência que lhe é subjacente. Decerto tal tarefa exigiria um labor intelectual que não cabe no âmbito de um artigo; no entanto, é possível fazer alguns apontamentos para posterior elaboração teórico-conceitual.

A seguir, partiremos do suposto de que duas tarefas sociológicas se impõem: (a) é preciso pensar a tecnologia moderna a partir da noção fenomenológica de corporificação; (b) para tanto, é preciso suplantar a noção da técnica como mero esquecimento do ser, o que implica pensar a suplementaridade técnica como traço constitutivo do humano. ${ }^{1}$

Se tomarmos os apontamentos da fenomenologia e da filosofia da tecnologia como base para o entendimento das conexões entre as noções de experiência e tecnologia, temos o seguinte enunciado geral: a técnica, assim como a ciência, está encerrada num projeto matematizante que 'esquece' o ser corporal-perceptivo dos humanos em um mundo-da-vida histórico-cultural (IHDE, 2004, p. 22). Tal percepção, entretanto, não deixa de guardar ambigüidades, pois que a própria fenomenologia, sobretudo na vertente de Merleau-Ponty, sugere a existência de processos de corporificação nos quais há uma zona de indiferenciação entre seres humanos e objetos técnicos. A 'relação corporificada' significa um senso de aptidão corporalmente ampliado através de um artefato, como dirá Don Ihde a partir da seguinte citação de MerleauPonty:

\begin{abstract}
A bengala de um cego deixou de ser um objeto para ele e não é mais percebida em si, o seu bico tornou-se a área de sensibilidade, ampliando $\mathrm{o}$ alcance e o raio ativo de toque e fornecendo um paralelo à visão. $\mathrm{Na}$ exploração das coisas, o cumprimento da bengala não entra expressamente como um meio termo: o cego sente a bengala através da posição dos objetos e não a posição dos objetos através dela (MERLEAU-PONTY apud IHDE, 2004, p. 23).
\end{abstract}

\footnotetext{
${ }^{2}$ Quanto a este último aspecto, procuro me alinhar aos desenvolvimentos teóricos recentes esboçados em FERREIRA, 2004; e FERREIRA; AMARAL JR., 2004.
} 
Até meados do século XX, a fenomenologia oscilará entre a atenção a processos de corporificação e a noção de ciência como projeto matematizante. Com Heidegger essa segunda vertente ganharia força. Conhecemos o argumento heideggeriano segundo o qual a técnica promove o esquecimento do ser. Em A questão da técnica (2002) Heidegger apontará uma guinada radical no papel da técnica a partir da modernidade. No período pré-moderno a técnica estava associada a um processo de desencobrimento do real característico tanto da arte quanto da produção na natureza. A interpelação da natureza pelo homem erigia um modelo de produção voltado para a provisão. Com a tecnologia moderna teríamos um fenômeno radicalmente distinto, na medida em que tal interpelação da natureza ocorre não mais a partir de uma lógica de provisão, mas de acumulação e controle.

A saída antropocêntrica oferecida pela tradição marxista à refuncionalização da técnica na modernidade é bastante conhecida: a luta de classes deverá se orientar pela busca do controle dos meios de produção da vida material e a tarefa histórico-trágica do proletariado é abolir a propriedade de tais meios. Embora a perspectiva marxiana ganhe em pertinência sociológica e empírica, não podemos desconsiderar que Heidegger oferece uma interpretação ao mesmo tempo profícua e inquietante: se na era pré-moderna o homem dispõe da natureza a partir da técnica, na modernidade o homem também passa a ser disposto pela técnica. Em Marx o impulso acumulativo da técnica se deve ao desenvolvimento da racionalidade capitalista, ao passo que em Heidegger tal impulso escapa ao próprio homem - e notemos que, curiosa e intrigantemente, o filósofo de Heidelberg parece ignorar deliberadamente o papel exercido pelo capitalismo na refuncionalização da técnica ${ }^{2}$. Mas a partir de que argumento se pode dizer que o próprio homem passa a ser disposto pela técnica?

Heidegger utiliza o termo gestell para dar conta do apelo explorador característico da técnica moderna. Gestell é pensado como um chamado, aquilo que leva o homem a explorar, pela técnica, a natureza a fim de deixar todas as coisas em estado de disponibilidade [bestand] para uso posterior indefinido. O termo também é central para se pensar como esse apelo explorador nos escapa, pois que o próprio homem pertence à disponibilidade, pela técnica. Daí o enunciado segundo o qual a técnica é o equívoco da metafísica - o que não exime o próprio Heidegger de incorrer em expediente metafísico (IHDE, 2004). Se gestell designa uma lógica de acúmulo e controle que é subordinada em última instância a uma vontade de vontade, como quer Heidegger, a questão da essência da técnica só poderá ser resolvida no âmbito da metafísica. Não obstante o caráter demasiado abstrato desta abordagem, não podemos deixar de reconhecer que ela conheceu adeptos ao longo do século XX, mesmo antes de Heidegger. Basta aludirmos de passagem ao motivo weberiano do desencantamento do mundo e ao seu pessimismo quanto aos desenvolvimentos da racionalidade ocidental por todos os domínios da vida cotidiana. Assim como, pensemos na influência de Heidegger sobre os teóricos frankfurtianos, sobretudo a discussão de Marcuse em torno da unidimensionalidade do homem (1973).

Toda essa discussão ganha relevância teórica e política na contemporaneidade. É crescente a percepção de que o desenvolvimento das tecnologias digitais da informação e da vida tem promovido um imbricamento cada vez maior entre o humano e o técnico, a ponto de hoje falar-se na categoria pós-humano como algo que requer alguma validade no léxico das ciências humanas (Cf. HAYLES, 1999). O apelo por processos de corporificação (embodiment) no campo da tecnocultura tem tomado direções que parecem desabilitar qualquer tentativa de salvaguarda da concepção do corpo humano como algo que se constitui à margem de um aparato tecnológico. Tal sensação é reforçada quando deparamos com os andamentos em curso no plano da biotecnologia, que enfeixa uma gama de instâncias de produção de conhecimentos que têm

\footnotetext{
${ }^{3}$ E parecia ter razões para tanto. Heidegger viveu o suficiente para constatar que não só sob a vigência do capitalismo, mas também do socialismo stalinista e do nazi-fascismo europeu, o humano não passava de um resíduo da tecnologia.
} 
desafiado a intenção humanista de delimitação de fronteiras entre o orgânico e o artificial, o natural e o técnico, o humano e o vegetal e o animal.

Sem emitir de pronto algum juízo de valor a respeito da validade e da operacionalidade da categoria pós-humano, gostaríamos de discutir algumas implicações que ela enseja para se pensar a relação entre tecnologia e experiência na contemporaneidade. A primeira implicação é que o humanismo moderno parece definitivamente diante de uma aporia:

[...] aquilo que o humanismo oferece como fundamento de sociabilidade constituiria um limite que estaria efetivamente sendo cruzado pela digitalização da realidade, pela simulação, pela cibernética. Quer seja moderno o humanismo de que se fala, portador de um projeto político e ético que se legitima em torno da idéia de consciência livre e autônoma, quer se trate de um humanismo greco-latino, que elabora a estreita relação entre a condição humana e o logos, viveríamos um momento de ruptura (FERREIRA, 2004, p. 34).

Como desdobramento de tal assertiva, deparamos com a necessidade política premente de situar o patamar normativo sobre o qual se estrutura a tecnociência contemporânea. Em alguma medida, a interpretação heideggeriana parece atual: não só a natureza é submetida à operação matematizante, a um princípio de identidade que promove um saber de antemão; o humano também o é. A partir do momento em que a vida orgânica - seja ela humana, animal ou vegetal é tomada como uma matriz informacional, que tipo de promessa emancipatória nos aguarda? Precisamente aqui reside o ponto de minha reflexão: que tipo de experiência é possível num cenário político e científico em que a filosofia da consciência malogrou em seu humanismo tecnofóbico? Como é sabido, a resposta habermasiana será uma tentativa de salvaguardar o humanismo desautorizando a filosofia da consciência que lhe dá fundamento. No entanto, Habermas parece incorrer no mesmo expediente em que a fenomenologia já incorerra, ao sustentar uma oposição entre ciência e mundo-da-vida. Tal oposição parece não demonstrar muita eficácia política na contemporaneidade (cf. HABERMAS, 2004). Entre os adeptos da chamada guinada empírica na fenomenologia contemporânea, há a convicção de que é preciso reconhecer as áreas de confluência entre essa corrente e a filosofia da tecnologia. O principal ponto de confluência parece ser a idéia de que é preciso pensar a ciência dentro de um mundoda-vida, e não como instância que lhe é autônoma e antagônica. Basta pensarmos aqui em intervenções intelectuais que buscam situar a ciência como uma entre as diversas práticas de um mundo-da-vida (IHDE, 2004), ou que exploram o potencial político emancipatório ensejado pelas novas tecnologias para a libertação do feminino da opressão do masculino (HARAWAY, 1991). A inversão da dicotomia entre ciência e mundo-da-vida abre-nos um horizonte a partir do qual vislumbram-se ganhos políticos, pois que instaura a ambigüidade no modus operandi da ciência moderna. Em outros termos, a ciência situa-se entre as formas humanas de engajamento técnico com o mundo. Neste sentido, como no dizer de Jonatas Ferreira (2004), a técnica não é apenas esquecimento do ser, mas também abertura do ser para o mundo.

Em busca então de um patamar conceitual a partir do qual possamos vislumbrar o modo como a técnica pode se nos apresentar como instância de abertura do humano para o mundo, vejamos como a noção de experiência pode ser retomada a partir da lógica derridiana do suplemento. Ou, em outras palavras, vejamos se é possível falar em algo como experiência do suplemento para designar as relações do humano com a tecnologia na contemporaneidade.

\section{Tecnologia e humanismo}


Comecemos com a problematização feita por Derrida a respeito do modo como o humanismo clássico elaborou a relação entre fala e escrita, para percebermos posteriormente como essa relação reverbera nas fronteiras que o humanismo moderno delimita entre o técnico e o humano. Aquilo que Derrida chama efeito de platonismo é o ato de não deixar ver a complementaridade existente entre fala e escrita, entre memória e suporte externo. A passagem abaixo, transcrita por Derrida em A farmácia de Platão (1997, p. 49), relata o momento em que, no diálogo Fedro, o rei Thamous - em resposta a Theuth, pai da escritura - condena a escritura como algo maléfico à memória:

\begin{abstract}
E o rei replicou: "Incomparável mestre em artes, oh Theuth [...], uma coisa é o homem capaz de trazer à luz a fundação de uma arte, outra aquele que é capaz de apreciar o que esta arte comporta de prejuízo ou utilidade para os homens que deverão fazer uso dela. Neste momento, eis que em tua qualidade de pai dos caracteres da escritura [...], atribuístelhes, por complacência para com eles, todo o contrário de seus verdadeiros efeitos! Pois este conhecimento terá, como resultado, naqueles que o terão adquirido, tornar suas almas esquecidas, uma vez que cessarão de exercer sua memória [...]: depositando, com efeito, sua confiança no escrito, é do fora, graças a marcas externas [...], e não do dentro e graças a si mesmos, que se rememorarão das coisas [...]".
\end{abstract}

Para a filosofia platônica, tratar da relação entre escrita e memória é tratar da própria questão do conhecimento e da verdade. Sua teoria do conhecimento pré-natal tem como base a idéia de que há uma base de conhecimento extraterrena que é roubada aos humanos no ato do nascimento (Cf. WEINRICH, 2001, p. 42-9). Todo o processo de conhecimento e aprendizagem levado a cabo pelos indivíduos em vida teria como intenção recuperar um conhecimento pré-existente na alma, que assenta no próprio indivíduo, mas ele esqueceu. Conhecer é recordar. ${ }^{3}$ Pelo exemplo acima, vimos como a escrita, como suporte externo, não é aconselhável para Platão para realizar a tarefa do conhecimento. Por vias tortas chegamos à constatação de que aqui a escrita, como suporte técnico, promove um desvelamento do real - desvelamento nocivo, entretanto, pois que conduz ao engodo. Na relação traçada entre o humano e o logos, o humanismo clássico prega que a transmissão do conhecimento não pode ser confiada à técnica.

A desconfiança na escrita como suporte de memória adquire vários formatos no imaginário ocidental. Vejamos um exemplo da atualização desse imaginário em plagas tupiniquins. Na Zona da Mata de Pernambuco, corria, na primeira metade do século passado, a história de uma cabeça de cangaceiro que fora negociada e exposta na estação de trem da cidade de Palmares. Não fosse a maldição que encerra, a lenda seria apenas mais um registro do período em que eram comuns os relatos de confrontos entre o cangaço e as forças de repressão policial - mais conhecidas como Volante. Embora atos assim cruéis não fossem de espantar tanto entre cangaceiros quanto

\footnotetext{
${ }^{3}$ Em ensaio profícuo, Howard Caygill (1999) demonstra como a concepção hierárquica de memória e arquivo presente no diálogo Meno, de Platão, guarda incríveis similaridades com a concepção de memória presente nas hierarquias de acesso aos arquivos da World Wide Web. Caygill sustenta haver uma linha de continuidade entre as formulações dos criadores da www e o referido diálogo platônico: a tensão entre uma cultura hierárquica de memória e uma outra, que prima pela lateralidade nas operações de acesso ao arquivo.
} 
entre os membros da Volante, criou-se uma misteriosa maldição em torno dessa narrativa particular, que teria impactos no meio literário brasileiro. A maldição consistia no seguinte: a história da cabeça decepada jamais poderia ser contada por escrito, sob pena de aquele que ousasse fazê-lo ser vitimado de morte.

Em 1976, o escritor pernambucano Osman Lins - que ouvira a 'fábula macabra' durante a infância na zona rural de Vitória de Santo Antão, sua cidade natal - resolve incluí-la no centro do enredo do seu romance $A$ cabeça levada em triunfo. Cauteloso, Osman Lins relata seu intento ao amigo e teatrólogo Hermilo Borba Filho, que também conhecia a lenda desde a infância, pois que era natural de Palmares. Surge então um pacto ente os dois: Osman iniciaria o seu livro e Hermilo se compremeteria a também narrar a história num seu romance ou peça. O desfecho do pacto entre os amigos não poderia ser mais assustador: Hermilo morre no mesmo ano - em junho de 1976 -, sem sequer começar o seu relato; dois anos mais tarde Osman Lins seria acometido de um câncer generalizado que o levaria à morte, no momento em que alcançava as cento e quarenta páginas da versão inicial de A cabeça levada em triunfo. Conta-se ainda que antes de Osman e Hermilo dois cordelistas haviam empreendido a mesma tarefa. Tiveram a mesma sorte.

Sem dúvida a fábula é ilustrativa de uma determinada relação entre escrita e oralidade que é característica da cultura ocidental. Tal desconfiança reside precisamente na constatação de que a escrita exerce um efeito errante e desterritorializador em relação à fala, à oralidade. A denegação da escrita conhece vários estágios ao longo do tempo, e seria ocioso, quando não impossível, estabelecer os principais momentos históricos em que isso ocorre. Para a questão que anima o presente artigo, basta reconhecermos que a tradição sociológica por vezes reforça a denegação da escrita, a partir do seu reconhecimento como um suporte técnico que como tal está fadado à instrumentalização e a um desvirtuamento do logos. Ou seja, na medida em que a sociologia tem seu repertório conceitual disposto a partir de condições discursivas delineadas pelo imaginário ocidental, reforça a concepção tecnofóbica presente na formulação clássica da relação entre o humano e o logos.

Houve um momento nas ciências humanas, sobretudo a partir do pós-segunda guerra, em que a denegação dos registros escritos tinha uma razão política óbvia. Os arquivos públicos oficiais não possibilitavam que se tivesse acesso às narrativas de grupos que sofreram na pele os rigores do nazismo e do fascismo. A busca por um método que primasse pelo resgate da transmissão oral das narrativas desses grupos foi um dos leitmotivs básicos da chamada história oral. E foram notáveis os ganhos políticos e metodológicos obtidos com essa estratégia.

Alguns eventos políticos característicos da sociedade da informação têm apontado, entretanto, para a necessidade de uma nova guinada no trato com a relação entre escrita e oralidade no interior das ciências humanas. Não se trata de questionar a capacidade que a história oral teve de auxiliar no entendimento da retomada da constituição da identidade de determinadas coletividades, mas de reconhecer que a escrita, sobretudo a escrita eletrônica, tem sido cada vez mais constitutiva da identidade de grupos sociais e de novos atores políticos (POSTER, 1990). É inquestionável que as recentes tecnologias da informação têm cada vez mais delimitado os cenários dos antagonismos sociais que levam a temas hoje recorrentes entre os cientistas sociais, como políticas de identidade e descentramento do sujeito.

Contudo, aí deparamos com o seguinte problema: se de um lado o humanismo clássico pensa uma relação entre o humano e o logos como algo imune à interferência do técnico; de outro lado os adeptos do pós-humanismo parecem fazer reverberar ecos da epistemologia cartesiana, ao pressupor uma apartação entre a consciência e a corporeidade do pensar (FERREIRA, 2004). Ao enveredar por essa via, tem-se uma visão unilateral dos processos de corporificação, e reforça-se a suposição de que a técnica implica em esquecimento do ser. Pretendemos que nosso argumento siga uma via inversa. É possível alargar as categorias de entendimento da relação entre o humano 
e o técnico para além de uma concepção da técnica como supressão do humano. Uma coisa é afirmar que o humano é disposto pela técnica, outra é dizer que tal submissão não vem de fora, de uma vontade metafísica, mas dos mecanismos de dominação instaurados pelos próprios seres humanos. Afinal, um traço característico do humanismo é estruturar um modelo de observação da realidade em que somos ao mesmo tempo sujeito e objeto da investigação e do controle.

Ao discutir a validade da categoria de biopoder de Foucault para o entendimento desse conjunto de questões, Jonatas Ferreira (2004) afirma:

O conhecimento tecnocientífico institui um espaço de poder em que podemos nos colocar alternadamente como controladores e controlados. É precisamente essa qualidade do espaço político moderno que faz o ato de vigiar mais eficiente que o de punir, é ela que garante a internalização do controle político. Assim, a ciência moderna expande-se, não como higienização dessa ambigüidade fundamental, mas a partir dela.

Como sabemos, a noção de biopoder e os dispositivos de poder e vigilância que ela procura dar conta tem como pressuposto a inteireza dos corpos, algo que parece em cheque diante das atuais tecnologias da vida. No entanto, a validade da categoria criada por Foucault permanece, mesmo quando a tecnociência opera a indistinção entre o humano, o animal e o vegetal. A partir dela é possível pensar os desenvolvimentos tecnológicos recentes como extensão da ambigüidade constitutiva da ciência moderna. No plano das especulações em torno da experiência, a ambigüidade que seria então característica da tecnocultura contemporânea parece nos atirar numa política da contingência, afinal, um dos temas de primeira ordem da agenda política dos estados nacionais na atualidade é definir o que vem a ser o humano diante das possibilidades de criação e potencialização da vida pela técnica.

Neste cenário, uma das poucas premissas que parecem gozar de certa credibilidade é aquela segundo a qual o próprio acesso ao real é hoje mediado pela tecnologia. Neste ponto Walter Benjamin tem contribuições anteriores as de Foucault. A sua discussão em torno da redefinição da experiência na modernidade já dava conta do fato de que, na era da reprodutibilidade técnica, a técnica seria tanto mais eficaz quanto mais ela nos desse um acesso mediado ao real sob a aparência de um acesso imediato (Cf. BENJAMIN, 1994). Num primeiro momento então Benjamin permite que visualizemos um momento de crise instaurado no seio do humanismo. Tal crise reside no impacto provocado pelos desenvolvimentos tecnológicos sobre a organização da experiência, cujo principal sintoma seria o impacto específico da reprodutibilidade técnica sobre a obra de arte. Poderíamos inclusive dizer que a fábula do cavaleiro sem cabeça é um sintoma deste fenômeno. Num segundo momento, ele propõe que a redefinição da obra de arte fornece um ponto de experimentação para a futura adaptação da humanidade com a tecnologia, ou ainda, exige que se pense a adaptação mútua entre tecnologia e organização social (CAYGILL, 1998, p. 117). A partir daí, os modos de organização da experiência dependem da compreensão que se tem da relação entre política e tecnologia (CAYGILL, 1998, p. 117).

A atualidade da maldição envolvendo Osman Lins e Hermilo Borba Filho só vingaria na época denominada por Benjamin de aurática, em que a legitimidade da experiência artística era dada pelo aqui-e-agora da produção. Experiência estética cujo sentido tem de ser transmitido em presença do autor, e segue a lógica do ritual. O que seria característico da era da reprodutibilidade técnica é o fato de que, no ato da reprodutibilidade, o aqui-e-agora do objeto reproduzido sai de cena. Se por um lado isso é similar à experiência da alienação do trabalhador em relação ao produto do seu trabalho na esfera da produção material, por outro lado, no campo 
da experiência estética, a desterritorialização dos eventos transmitidos é a condição de emergência da política e da politização da arte, de desprendimento dos objetos do crivo da tradição.

Benjamin demonstra que a tecnologia exerce o efeito de retirar do nosso raio de expectativas a fruição da 'experiência original', a atualização do momento autêntico que forneceria a chave para uma sociabilidade essencialmente humana - imune à técnica. Ao invés de isso nos privar da experiência, abre, ao contrário, novas possibilidades para vivenciá-la. Já foi dito noutra parte que Benjamin não chega a oferecer um apontamento teórico mais sistemático a respeito do assunto (FERREIRA; AMARAL JR., 2004). Ainda assim, não se lhe podemos negar o mérito de ter operado uma inversão na lógica platônica que prescreve a condenação da escrita por seu caráter mimético.

Para os apontamos do presente artigo, duas questões merecem destaque. A primeira é que a redefinição da experiência na modernidade parece avançar para um horizonte em que essa experiência passa a ser pensada a partir da suplementaridade técnica constitutiva do humano. Até aqui aceitamos de bom grado a operação da fenomenologia contemporânea de incluir a tecnocultura contemporânea em ambientes específicos do mundo-da-vida. Porém, e nisso reside a segunda questão, o que vem a ser de fato a experiência da contingência a que a tecnocultura contemporânea nos expõe?

\section{Suplemento, corporificação e experiência}

Temos em Benjamin a antecipação do que será posteriormente desenvolvido por um Derrida: a escrita deriva de um impulso mimético comum a qualquer inscrição (GAGNEBIN, 1997, p. 100). E como o momento de inscrição é sempre instituinte, ou seja, nenhum sentido prévio lhe subjaz, a atividade mimética não se reduzirá à mera imitação. Assim, embora não possamos vislumbrar maiores detalhes do sensorialismo da nova experiência tecnocultural na obra de Benjamin, através dela podemos perceber que quanto mais a tecnologia delimita cenários para a vida humana, mais fica claro que o sentido dos eventos só nos é oferecido alegoricamente.

A crítica derridiana ao logo-fonocentrismo ocidental tem implicações diretas para o tratamento destas questões. Pensemos na relação fala/escrita, tão exaustivamente abordada por Derrida. Por trás da predominância, atribuída pela filosofia socrática, da fala sobre a escrita está em jogo a noção segundo a qual a primeira nos aproximaria da experiência pura e da memória orgânica, ao passo que a segunda exerceria um efeito desterritorializador maléfico. Vem dessa oposição entre fala/escritura a oposição entre memória (mnéme) e hupomnésis. A escritura seria sempre um suporte externo de memória, que representaria o momento em que a memória orgânica tem que sucumbir a algum suporte externo. Para Derrida esse suporte é o arquivo, o lugar de consignação da memória que, ao registrar os eventos dignos de memorização, também os institui. Ao realçar as instâncias conservadora e institutriz do arquivo, Derrida vê no suporte externo a capacidade mesma de memorização, a não distinção entre memória orgânica e princípio hipomnético. Tratase então de tratar o arquivo como prótese do dentro, um suporte suplementar e coextensivo da memória humana.

Pensemos na viabilidade deste argumento a partir do exemplo do personagem Leonard no filme Amnésia, dirigido por Christopher Nolan e inspirado no conto "Memento mori”, de Jonathan Nolan. Não será descabido supor que grande parte da trama tanto do conto quanto do filme pode ser entendida a partir da relação sempre tensa e ambígua entre escrita e memória, tendo como 
pano-de-fundo a questão da vida. No conto, o fato de o personagem ter passado a depender de registros escritos no próprio corpo como possibilidade de articulação de ações as mais triviais é visto como algo que lhe priva da vida - ao menos de uma vida orgânica, natural. O próprio título enseja esta constatação: "lembra-te de morrer"; ou seja, não existe vida numa situação de dependência estrita do recurso a suportes externos de memória.

No filme, o diretor nos oferece outras possibilidades de interpretação. A conclusão a respeito do êxito ou não do personagem em conseguir organizar a vida cotidiana a partir dos suportes externos de memória dependerá de uma interpretação das possibilidades abertas pela narrativa. Não se sabe ao certo - ou ao menos o espectador é levado a escolher entre, no mínimo, duas possibilidades - se o personagem teve mesmo a esposa estuprada e seu esquecimento de eventos recentes adveio da pancada tomada na cabeça ao tentar salvá-la, ou, por outra, se ele próprio não terá matado a esposa injetando-lhe uma dose alta de insulina (e nesse caso a patologia de Sammy Jankins seria um artifício inconsciente ou uma fantasia encontrada por Leonard para escamotear seu próprio ato). $\mathrm{O}$ fato é que em ambos os casos o personagem é levado a estabelecer, por uma questão de vida ou morte, uma confiança total na própria capacidade de memorização. E como tal capacidade é limitada pelo esquecimento dos eventos recentes, a escrita no próprio corpo é sua única condição de... manter-se vivo.

Afirmamos que a conclusão a respeito de se Leonard desfruta ou não de vida depende de um ponto de vista relativo ao estatuto do aspecto mimético da escrita. Pois se a escrita for vista como algo que deve guardar fidelidade a algum plano do real, do verdadeiro, do originário, parece difícil conceder a condição de ser vivo ao nosso Leonard, visto que a própria 'origem dos fatos' é ambígua no filme (note-se que aqui o que menos importa é a sobrevivência biológica do indivíduo, e sim sua capacidade de atribuição de sentido às coisas). Por outra via, se concedermos primazia ao aspecto instituinte da escrita, veremos todo o potencial mimético desenvolvido por Leonard ao conseguir atribuir sentido aos seus atos a partir da memorização por meio dos registros escritos no corpo. Se optar pela segunda interpretação, o leitor terá se afastado do Platão do diálogo Fedro, para quem a escrita não é uma instância confiável para a tomada de decisões, e terá pactuado com Benjamin e sobretudo Derrida, pois que para ambos não existe sentido prévio a determinar a escrita.

O que está em jogo na discussão ensejada pelo filme e pelo conto é a própria tarefa de reapresentação freqüentemente atribuída à escrita. E, neste sentido, Derrida possibilita que avancemos no entendimento dos redimensionamentos contemporâneos operados nesta 'tarefa'. Ao tratar do potencial instaurado pelas novas tecnologias de informação no que diz respeito às possibilidades de arquivamento, ele detecta a possibilidade de revolução na própria representação do aparelho psíquico. Senão vejamos: "Pois se as reviravoltas atuais afetassem as estruturas mesmas do aparelho psíquico, por exemplo, em sua arquitetura espacial e em sua economia de velocidade, em seu tratamento do espaço e da temporalização, não se trataria mais de um simples progresso contínuo na representação, no valor representativo do modelo mas de toda uma outra lógica" (DERRIDA, 2001, p. 27). Essa outra lógica consiste na superação originária com a própria idéia de natureza, de uma memória orgânica compromissada com a origem. $\mathrm{O}$ arquivo, assim como a escritura, marcaria a ruptura com a arkhê, com a possibilidade de retorno a uma origem primeva. Daí a acusação, de colorido platônico, de que a escritura está fadada à mera repetição anacrônica de enunciados - "repetir sem saber" (DERRIDA, 1997, p. 18). Em Derrida o 'repetir sem saber' parece fora de questão, pois a mímesis não participa do ser verdadeiro, o que exige que pensemos novos critérios de julgamento do papel da escrita.

Podemos aqui estender o caráter desterritorializador e errante que Derrida atribui à técnica e à escrita ao suporte mnemotécnico. Se a escrita já quebrara as pretensões de se tratar o discurso como algo guiado por início, meio e fim, como algo análogo ao organismo humano, o que se postula é a própria possibilidade de perceber no (hiper)texto e no arquivo a potencial quebra com 
a idéia de vida natural. Aqui mais uma vez teríamos um encontro potencial entre Benjamin e Derrida, afinal o primeiro já teria demonstrado desde o Drama barroco que o fim no romance moderno não é mais capaz de justificar e dar sentido a uma vida, fornecer os acabamentos de uma memória, como acontecia com o gênero trágico. Voltando ao filme Amnésia, não precisamos de uma narrativa linear para nos comover com o drama vivenciado pelo pobre Leonard. A própria seqüência desobedece à ordem linear, e, mais uma vez, seu encadeamento parece a cargo da escolha do espectador com relação a pelo menos duas possibilidades. $\mathrm{O}$ sentido da trama (e da própria vida) é dado pela capacidade mimética do personagem, não há espera por um final redentor e esclarecedor. E ainda, não há distinção entre corpo e arquivo, entre memória orgânica e hipomnética.

O exemplo do filme também é esclarecedor das possibilidades, incertezas e traumas que uma política da contingência encerra. Na impossibilidade de estabelecimento ou recuperação de uma arkhê, a escrita cada vez mais se nos oferece como instância a partir da qual lidamos com a contingência da vida, o esforço sempre hercúleo de atribuição de sentido ao aspecto acidental da existência.

Derrida desmistifica a idéia de que o ato de confiar a memória a marcas externas constitui um remédio maléfico à memorização e à lembrança. Mas o problema se anuncia ainda mais problemático. Ocorre que, para Derrida, no próprio ato de memorização atua a desmemória - o paradoxo da desmemoriação pelo suporte de memória. Na conservação/instituição mesma da memória, no momento da rememoração e da repetição, instala-se o esquecimento. Para compreender esta estranha economia arquival se faz necessário compreender e situar a atuação de uma pulsão de morte, que caracteriza o inexorável desejo de memória, o mal de arquivo.

Talvez possamos dizer que a contribuição derridiana para as reflexões em torno da memória consiste em desautorizar a propensão a ver as novas técnicas de arquivamento como particularmente propiciadoras do esquecimento. Trata-se, antes, de perceber que toda inscrição mnemotécnica, todo princípio de arquivamento é ao mesmo tempo veículo de memória e de esquecimento. Mais ainda, trata-se de tentar perceber que tipo particular de experiência de memória, de temporalidade e de humanidade estes novos parâmetros de arquivamento nos abrem. Se nos for dado uma última aproximação com Benjamin, poderíamos dizer - como hipótese de trabalho a ser melhor esmiuçada noutro momento - que os motivos da alegoria e do mal de arquivo consistem numa outra maneira de abordar a questão do fetiche da mercadoria, de dar conta do fenômeno relativo à desvalorização dos objetos no momento mesmo em que são apresentados como novos. Nos termos de Benjamin: 'novidade' sempre prestes a se tornar sucata - a caducidade do presente como marca da modernidade (GAGNEBIN, 1997, p. 150-151).

\section{Considerações finais}

De volta ao argumento central desse texto, percebemos que a lógica derridiana do suplemento fornece subsídios teóricos para se pensar a relação constitutiva entre o humano e o técnico. E também para que se especule a respeito de toda uma gama de experiências que é dado aos seres humanos experimentar na contemporaneidade. Ao direcionar o argumento para a relação entre memória e escritura, pretendi demonstrar uma via a partir da qual é possível lidar com processos de corporificação. As diferentes leituras propiciadas pelo conto e pelo filme acima discutidos dão o tom das ambigüidades presentes nos processos de corporificação. Entre o reclame por um humano cuja constituição sensorial e subjetiva seja imune ao técnico, e a postulação de um humano constituído pela mediação técnica, há um vasto campo de experiências a ser explorado. 
Nossos posicionamentos teóricos e políticos em torno dos discursos humanistas ou póshumanistas terão como ponto de partida essa área movediça de entendimento.

Vimos que tratar a ciência como instância constitutiva dos nossos mundos-da-vida possibilita situar as ambigüidades que operam em seu próprio modus operandi, o que a dota de uma característica típica dos humanos: a falibilidade. Isso traz ganhos interpretativos em termos de compreender que o homem não é disposto pela técnica sob a injunção de uma força metafísica, mas de processos de conhecimento e de poder engendrados pelos próprios homens. Por outro lado, vimos também que essa evidência nos atira numa política da contingência. Em termos práticos, dizer que o projeto matematizante da ciência moderna comporta ambigüidades é abrirlhe os flancos para a intervenção do político. Porém, a arena do político parece ainda anuviada de concepções ufanistas e/ou catastróficas a respeito dos desenvolvimentos tecnológicos recentes.

A experiência da contingência a que está exposto o personagem Leonard parece ilustrativa do tipo de experiência a que estamos expostos na contemporaneidade. No momento em que se dá conta de que pode manipular a própria identidade e o rumo dos acontecimentos da sua vida a partir do recurso a um suporte mnemotécnico, ele experimenta uma falsa sensação de autonomia e arbítrio. O que decorre daí é uma sucessão de eventos que o levam a um círculo vicioso do qual é cada vez mais difícil sair. Não se experimenta de todo a sensação de que se pode dispor da técnica; logo vem a sensação de que também somos dispostos por ela. Ao menos em alguns casos, nos será dado a oportunidade de estabelecer uma relação mais pacífica com os suportes mnemotécnicos. Do contrário, não me teria sido possível retransmitir a lenda do cavaleiro sem cabeça por escrito. Duvido que hoje a maldição que acometeu Osman Lins e Hermilo Borba Filho se abata sobre alguém. Assim espero!

\section{Referências}

BENJAMIN, Walter. A obra de arte na era da reprodutibilidade técnica. In: . Magia e técnica, arte e política: ensaios sobre literatura e história da cultura. 7. ed. São Paulo: Brasiliense, 1994.

CAYGILL, Howard. Meno and the internet: between memory and the archive. History of the Human Sciences, v.12, n. 2, p. 1-11, 1999.

. Walter Benjamin: the colour of experience. London: Routledge, 1998.

DERRIDA, Jacques. A farmácia de Platão. 2. ed. São Paulo: Iluminuras, 1997.

. Gramatologia. 2. ed. São Paulo: Perspectiva, 1999.

. Mal de arquivo: uma impressão freudiana. Rio de Janeiro: Relume Dumará, 2001.

FERREIRA, Jonatas. A condição pós-humana: ou "como pular sobre nossa própria sombra". Política \& Trabalho, João Pessoa, n. 21, 2004.

FERREIRA, Jonatas; AMARAL JR., Aécio. Memória eletrônica e desterritorialização. Política \& Sociedade, Florianópolis, v. 1, n. 4, 2004. 
GAGNEBIN, Jeanne Marie. Sete aulas sobre linguagem, memória e história. Rio de Janeiro: Imago, 1997.

HABERMAS, Jürgen. O futuro da natureza humana: a caminho de uma eugenia liberal? São Paulo: Martins Fontes, 2004.

HARAWAY, Donna J. Ciencia, cyborgs y mujeres: la reinvención de la naturaleza. Madrid: Ediciones Cátedra, 1991.

HAYLES, N. Katherine. How we became posthuman: virtual bodies in cybernetics, literature, and informatics. Chicago: The University of Chicago Press, 1999.

HEIDEGGER, Martin. A questão da técnica. In: Ensaios e conferências. 2. ed. Petrópolis Vozes, 2002.

IHDE, Don. Incorporando a matéria: fenomenologia e filosofia da tecnologia. Política \& Trabalho, João Pessoa, n. 21, 2004.

MARCUSE, Herbert.. A ideologia da sociedade industrial: o homem unidimensional. Rio de Janeiro: J. Zahar, 1973.

POSTER, Mark. The mode of information: poststructuralism and social context. Cambridge: Polity Press, 1990.

WEINRICH, Harald. Lete: arte e crítica do esquecimento. Rio de Janeiro: Civilização Brasileira, 2001. 